\title{
Dual-Function Enzyme Catalysis for Enantioselective Carbon-Nitrogen Bond Formation
}

Zhen Liu ${ }^{1}$, Carla Calvó-Tusell ${ }^{2}$, Andrew Z. Zhou ${ }^{1}$, Kai Chen ${ }^{1,3 *}$, Marc Garcia-Borràs ${ }^{2 *}$ and Frances H. Arnold ${ }^{1 *}$

Chiral amines can be made by insertion of a carbene into an $\mathrm{N}-\mathrm{H}$ bond using two-catalyst systems that combine a transition metal carbene-transfer catalyst and a chiral proton-transfer catalyst to enforce stereocontrol. Haem proteins can effect carbene $\mathrm{N}-\mathrm{H}$ insertion, but asymmetric protonation in an active site replete with proton sources is challenging. Here we describe engineered cytochrome $\mathbf{P} 450$ enzymes that catalyze carbene $\mathrm{N}-\mathrm{H}$ insertion to prepare biologically relevant $\alpha$-amino lactones with high activity and enantioselectivity (up to 32,100 total turnovers, $>99 \%$ yield and $98 \%$ e.e.). These enzymes serve as dual-function catalysts, inducing carbene transfer and promoting the subsequent proton transfer with excellent stereoselectivity in a single active site. Computational studies uncover the detailed mechanism of this new-to-nature enzymatic reaction and explain how active-site residues accelerate this transformation and provide stereocontrol.

Amines are ubiquitous in bioactive molecules and functional materials ${ }^{1,2}$, and the development of efficient and selective methods for $\mathrm{C}-\mathrm{N}$ bond construction remains one of the central themes of modern organic chemistry and biochemistry ${ }^{3-5}$. Among the numerous ways to construct $\mathrm{C}-\mathrm{N}$ bonds, carbene insertion into $\mathrm{N}-\mathrm{H}$ bonds ${ }^{6-10}$ benefits from the high reactivity of carbene species and excellent functional group compatibility to rapidly build complex nitrogen-containing molecules. In the last several years, empowered by directed evolution, metallo-haem-dependent enzymes (cytochromes P450, cytochromes $c$ and globins, for example) have exhibited an impressive ability to catalyze non-natural carbene- and nitrene-transfer reactions with high efficiency and selectivity. Specifically, haem proteins have been engineered to perform carbene $\mathrm{N}-\mathrm{H}$ insertion reactions with catalytic efficiency far exceeding their small-molecule counterparts (up to thousands of total turnover numbers (TTN)) ${ }^{11-14}$. However, compared to cyclopropanation ${ }^{15}, \mathrm{C}-\mathrm{H}$ insertion ${ }^{16}$ and many other carbene transfer reactions also catalyzed by haem proteins ${ }^{17,18}, \mathrm{~N}-\mathrm{H}$ insertion reactions are still underdeveloped, especially with respect to high stereocontrol.

In small-molecule catalysis, a common strategy for asymmetric $\mathrm{N}-\mathrm{H}$ insertion is to employ a transition-metal catalyst for carbene transfer along with a separate chiral proton-transfer catalyst (PTC) for stereoinduction (Fig. 1a) ${ }^{19,20}$. The carbene precursor first reacts to form a metal carbene species, which can be trapped by the amine substrate through nucleophilic attack, generating an ylide intermediate. The asymmetric protonation of the ylide is then guided by a chiral PTC, such as a chiral phosphoric acid ${ }^{19}$ or amino-thiourea ${ }^{20}$; other proton sources need to be strictly avoided to ensure high asymmetric induction. Computational studies by Shaik and coworkers ${ }^{21}$ have revealed a similar mechanism for haem protein-catalyzed $\mathrm{N}-\mathrm{H}$ insertion reactions. Thus, the challenge in achieving high enantioselectivity originates from the difficulty in precisely controlling the protonation of highly

\footnotetext{
${ }^{1}$ Division of Chemistry and Chemical Engineering 210-41, California Institute of Technology, Pasadena, CA, USA. ${ }^{2}$ Institut de Química Computacional i Catàlisi and Departament de Química, Universitat de Girona, Girona, Catalonia, Spain. ${ }^{3}$ Current address: Innovative Genomics Institute, University of California, Berkeley, CA, USA. *e-mail: chenkaikc1990@gmail.com; marcgbq@gmail.com; frances@cheme.caltech.edu
} 
reactive ylide intermediates in an environment where the enzyme as well as water molecules are potential proton sources. The sole biocatalytic system for asymmetric $\mathrm{N}-\mathrm{H}$ insertion reported to date by Fasan ${ }^{13}$ used 2-diazopropanate benzyl esters and primary anilines with engineered myoglobins as the catalyst and achieved generally low to moderate enantiocontrol. By drawing an analogy to the dualcatalyst strategy used in small-molecule catalysis, we envisioned that a highly enantioselective biocatalytic $\mathrm{N}-\mathrm{H}$ insertion reaction would be possible if the enzyme can perform two distinct functions (Fig. 1b): 1) generate the carbene species, which triggers nucleophilic attack from amines, and 2) induce a selective proton-transfer event immediately after ylide formation in the enzyme active site.

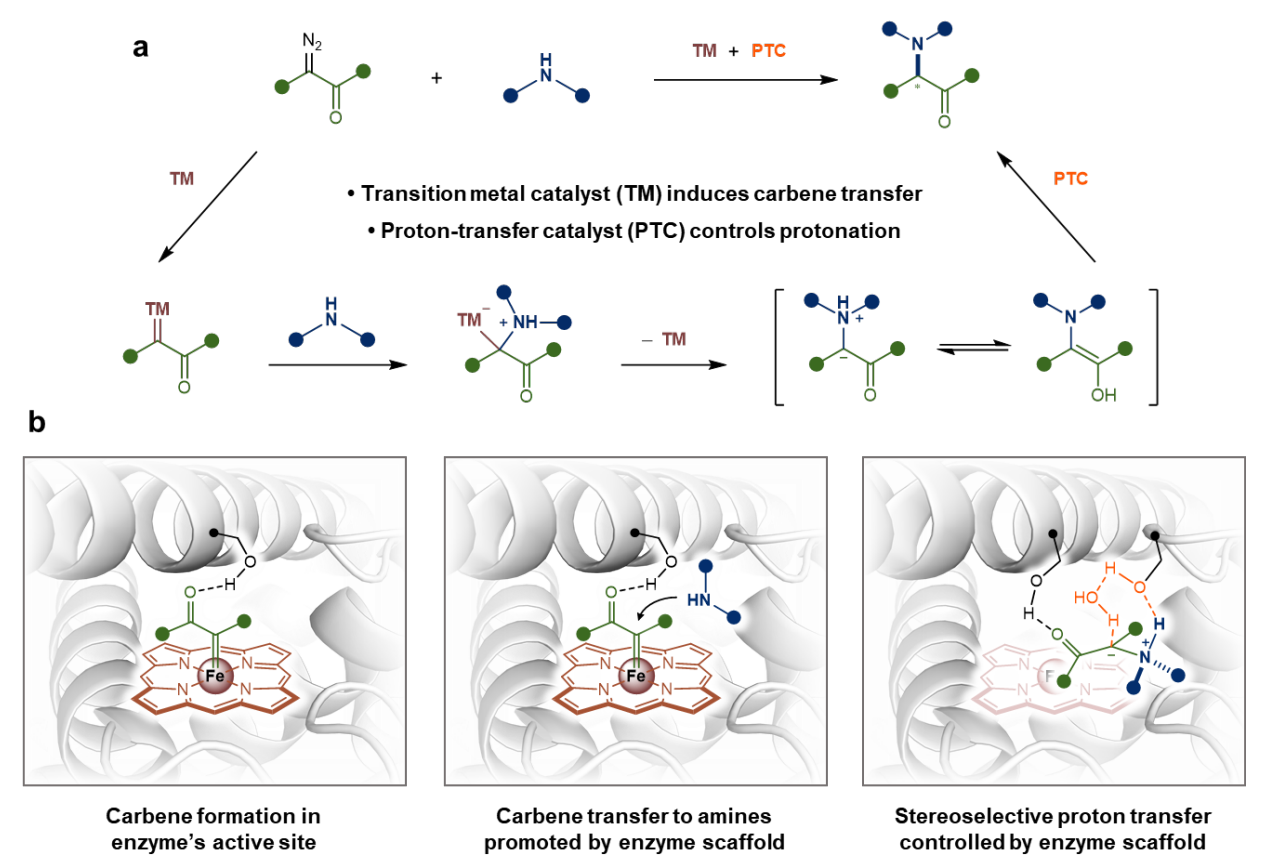

Fig. 1 | Asymmetric carbene $\mathbf{N}-\mathbf{H}$ insertion using small-molecule catalysts and enzymes. a, The proposed reaction mechanism for asymmetric $\mathrm{N}-\mathrm{H}$ insertion catalyzed by a transition-metal catalyst and a chiral PTC. b, Haem protein serves as a dual-function catalyst for enantioselective carbene $\mathrm{N}-\mathrm{H}$ insertion.

\section{Results and discussion}

We commenced this investigation of enzymatic carbene $\mathrm{N}-\mathrm{H}$ insertion by focusing on the reaction between lactone diazo 1 and $N$-methyl aniline 2a. This transformation is of particular interest as it is expected to afford a biologically relevant $\alpha$-amino lactone product $3 \mathbf{a}^{22}$. In addition, lactone-based carbenes are usually associated with undesired $\beta$-hydride elimination processes, and no small-molecule catalysts have been shown to afford precise stereocontrol using this type of carbene ${ }^{23,24}$. Our previous work, however, showed that engineered haem proteins could dramatically accelerate the desired lactone carbene-transfer process while circumventing undesired side reactions ${ }^{25,26}$. We thus focused on discovering an enzyme that not only facilitates the transfer of the lactone-carbene species to amines but also imposes stereocontrol in the subsequent proton transfer step to deliver an enantio-enriched product.

To this end, we screened a collection of 40 haem protein variants, previously evolved for different carbene and nitrene transformations, in the form of whole Escherichia coli (E. coli) cell catalysts (Fig. 2a) (See Supporting Information (SI) for details). While most of the variants only exhibited low levels of activity ( $<5 \%$ conversion), an FAD domain-truncated P411 variant (serine-ligated P450) L7 (well $\mathrm{C} 10 \mathrm{in} \mathrm{Fig.} \mathrm{2a),} \mathrm{generated} \mathrm{in} \mathrm{previous} \mathrm{engineering} \mathrm{efforts} \mathrm{for} \mathrm{lactone} \mathrm{carbene} \mathrm{C}-\mathrm{H}$ insertion ${ }^{26}$, catalyzed 
this $\mathrm{N}-\mathrm{H}$ insertion reaction with $81 \%$ yield and $94 \%$ enantiomeric excess (e.e.). Further evaluation of the enzyme lineage for lactone carbene $\mathrm{C}-\mathrm{H}$ insertion showed that both $\mathbf{L 6}$ and $\mathbf{L} 7$ were superior biocatalysts for this amination reaction compared to other variants in the same lineage (L1-L5) (Fig. 2b). Restoring $\mathbf{L} 7$ to a full-length P411 (L7_FL) by re-attaching its native P450 reductase domain further improved the catalytic performance of the enzyme, which generated product 3a in $92 \%$ yield and $95 \%$ e.e. The improvement may be due to the increased stability of the full-length protein ${ }^{27}$.

In going from $\mathbf{L 5}$ to L6, a single mutation A264S, had a dramatic impact on the $\mathrm{N}-\mathrm{H}$ insertion reaction, especially with respect to enantioselectivity (from $-21 \%$ to $92 \%$ e.e.) (Fig. 2 b). This observation indicates that the amino acid residue at site 264 , which is located above the haem cofactor, plays an important role in both promoting the lactone carbene-transfer process and exerting control over the enantio-determining step. We then prepared five variants based on the full-length version of $\mathbf{L 6}$, L6_FL, with different mutations at site 264 and evaluated their performance in the $\mathrm{N}-\mathrm{H}$ insertion reaction (Fig. 2c). Interestingly, mutation of serine to smaller amino acids (A or G) led to comparable activity but much lower selectivity, suggesting that the hydrophilic side chain of serine may be involved in controlling the enantioselectivity. However, protic residues of larger size (D, T and C) at site 264 are detrimental to both the yield and stereocontrol.
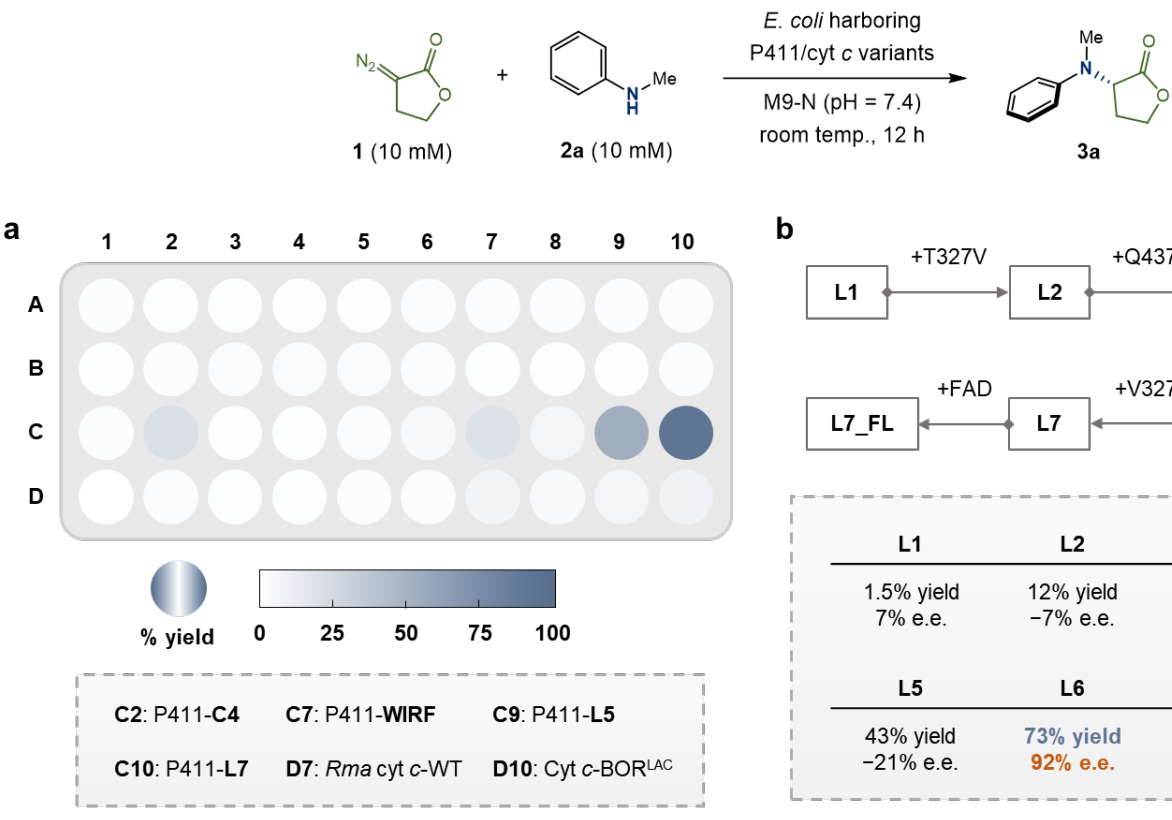

b

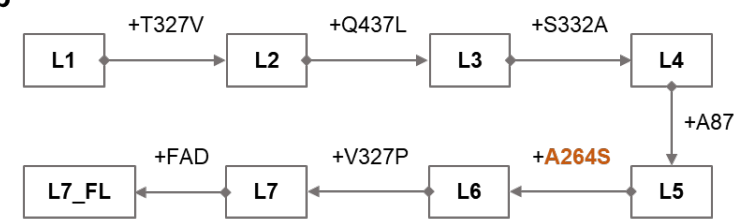

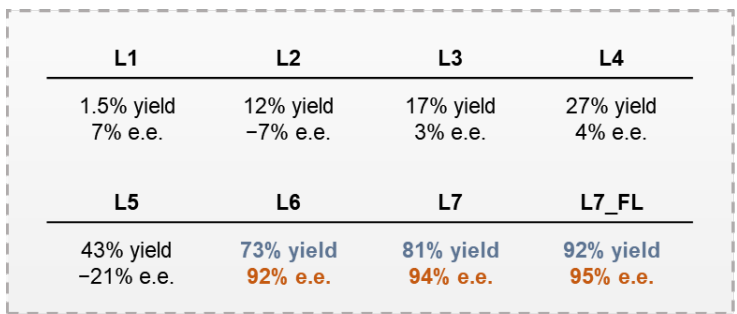

C
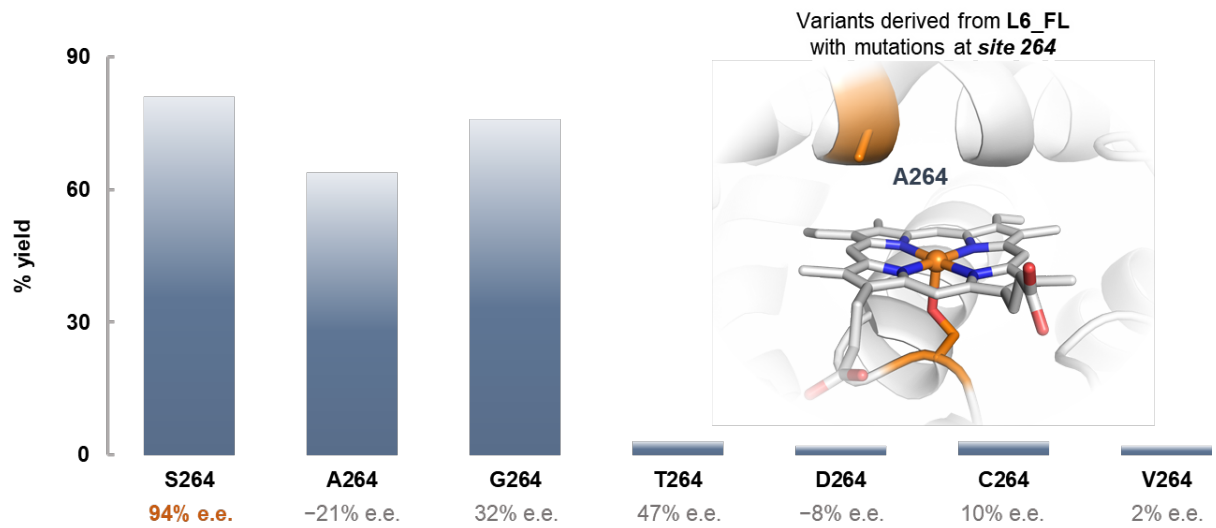

Fig. 2 Screen for enzymatic $\mathbf{N}-\mathrm{H}$ insertion with a haem protein collection and identification of A264S as the key mutation for achieving high activity and selectivity. a, Initial screening was 
performed with 40 haem protein variants, which led to the discovery of $\mathbf{L} 7$ (in well C10), which originated from a previous lactone carbene $\mathrm{C}-\mathrm{H}$ insertion project. $\mathbf{b}$, Rescreening of the lactone carbene $\mathrm{C}-\mathrm{H}$ insertion lineage. Variants with the A264S mutation were found to be excellent catalysts for $\mathrm{N}-\mathrm{H}$ insertion. c, Mutagenesis studies showed that replacing S264 with other amino acids led to low selectivities and diminished yields. Residue A264 in the active site of P411 variant E10 (PDB ID:5UCW) is highlighted. L7_FL and L6_FL are $\mathbf{L} 7$ and $\mathbf{L 6}$ restored to their respective full-length P411 enzymes.

We performed computational studies to understand the molecular basis of this enzymatic transformation and elucidate the role of S264 in promoting asymmetric carbene $\mathrm{N}-\mathrm{H}$ insertion. Extensive molecular dynamics (MD) simulations considering the haem domain of variant $\mathbf{L 6}$ with the lactone-carbene bound showed that the lactone mainly explores a single orientation in the active site of L6. This is stabilized by the S264 side chain that establishes persistent H-bonding interactions with the lactone ester group (Fig. 3a). Within this orientation, only one face of the electrophilic carbene can be attacked by the nucleophilic amine substrate, enantioselectively yielding a reactive ylide intermediate (see Fig. S14 for the complete reaction mechanism studied by density functional theory (DFT) model calculations). Simulations performed with variant $\mathbf{L} 7$ describe similar behavior, whereas equivalent modelling for $\mathbf{L 5}$ variant show that, in the absence of S264, the lactone explores multiple conformations (see Fig. S5). Furthermore, H-bonding interactions involving the carbonyl group of the carbene were found to enhance its electrophilicity (Fig. S15), in line with what was disclosed in previous work ${ }^{28,29}$. Consequently, in addition to controlling the carbene orientation, S264 also contributes to increasing the reactivity of the carbene species.

We then modelled the approach of amine substrate 2a to the carbene and the subsequent formation of the ylide intermediate in the active site of $\mathbf{L 6}$. Amine substrate binding in a near-attack conformation for the $N$-nucleophilic addition to the lactone carbene is stabilized by hydrophobic interactions between the substrate aromatic ring and active site hydrophobic residues (L75, V328, L437, P329), as observed from MD trajectories (see Fig. 3b, Fig. S6 and S7). The simulations also show that the H-bond between the lactone ester group and S264 is maintained when the ylide is formed. In addition, according to the simulations, only a few water molecules are present in the active site pocket, which are precisely funneled through two water channels, one formed by Y263 and T438 from the top face of the ylide lactone ring and the other one guided by the anionic haem carboxylates near the ylide amine group (Fig. 3c, Fig. S8 and S9). DFT calculations show that, once dissociated from the iron, the ylide intermediate can rapidly react with these water molecules to achieve the stereoselective proton rearrangement in the enzyme active site prior to product release: a water molecule protonates the ylide at the $\mathrm{C}$ position from the top face (pro- $S$ face) of the lactone ring while a second water deprotonates the amine group (Fig. $3 \mathrm{~d}$ and Fig. S18). The low activation barriers calculated indicate that this proton transfer step can take place immediately once the ylide dissociates from the iron. Collectively, the enantioselective formation of the ylide and the precise placement of water molecules in the active site for proton transfer enable the enzyme to control the selectivity of this $\mathrm{N}-\mathrm{H}$ insertion reaction. 

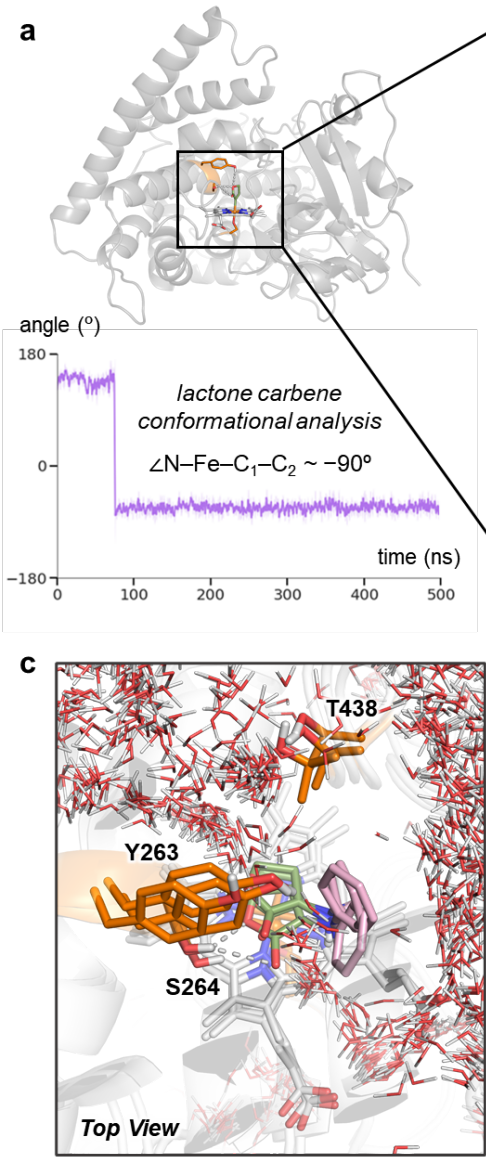
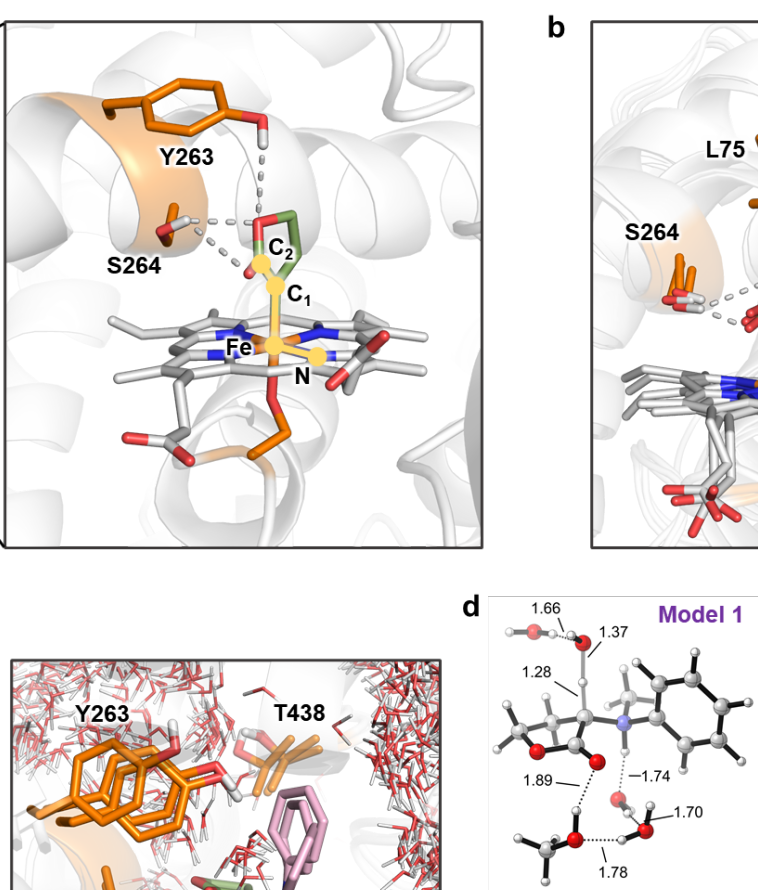

$\Delta \mathrm{G}^{\ddagger}=4.0 \mathrm{kcal} \cdot \mathrm{mol}^{-1}$

$\Delta \mathrm{G}^{ \pm}=7.7 \mathrm{kcal} \cdot \mathrm{mol}^{-1}$

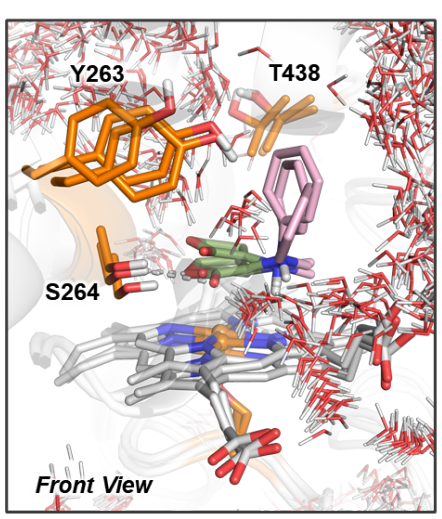

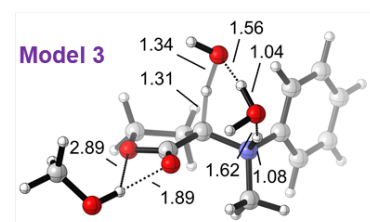

b
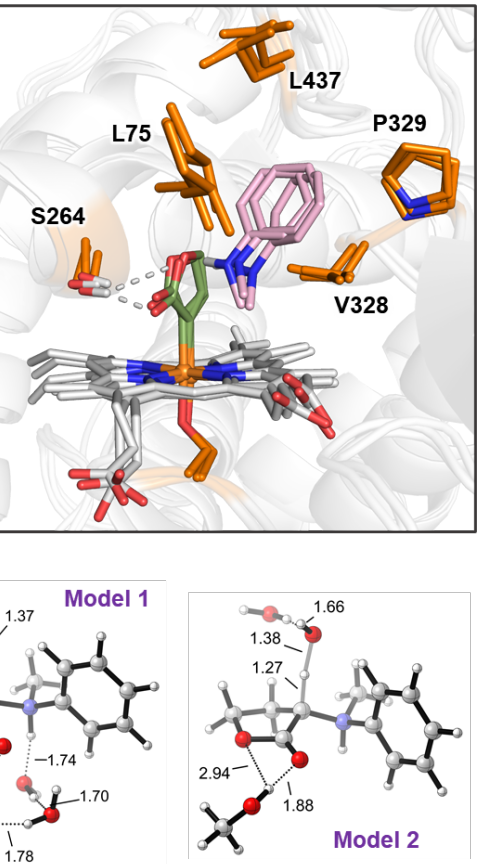

$\Delta \mathrm{G}^{\ddagger}=5.2 \mathrm{kcal} \cdot \mathrm{mol}^{-1}$

Fig. 3 | Computational modelling elucidates the origins of enantioselectivity of carbene transfer into $\mathrm{N}-\mathrm{H}$ bonds catalyzed by P411-L6. a, Representative snapshot from MD simulations describing the conformations explored by the lactone carbene in P411-L6. The $\angle\left(\mathrm{N}-\mathrm{Fe}-\mathrm{C}_{1}-\mathrm{C}_{2}\right)$ dihedral angle measured along the MD trajectory describes the relative orientation explored by the carbene (see SI for additional replicas). b, Overlay of three representative snapshots obtained from constrained-MD simulations exploring near attack conformations for the $N$-nucleophilic attack of 2a to the lactone carbene in L6. c, Overlay of three representative snapshots from constrained-MD simulations exploring L6 active site arrangement when ylide 2a is formed. Displayed water molecules are drawn from 25 random structures across the 100 ns MD trajectory. d, DFT-optimized model transition states (TS) for stereoselective ylide proton transfer. These models were built based on the arrangement of water molecules around the ylide intermediate in the $\mathbf{L 6}$ active site observed from MD simulations (see SI for details). Key distances are given in $\AA$.

We envisioned that the dual-function catalytic cavity of $\mathbf{L 7}$ 7FL could promote lactone-carbene transfer to other amine substrates with stereocontrol. Indeed, using lactone diazo compound $\mathbf{1}$ as the carbene precursor, a variety of amine nucleophiles could undergo the desired $\mathrm{N}-\mathrm{H}$ insertion reaction under our standard whole-cell reaction conditions $\left(\mathrm{OD}_{600}=30\right.$ in M9-N buffer), as summarized in Fig. 4. Secondary anilines bearing an $N$-alkyl group $(\mathbf{3 b}-\mathbf{g})$ were well tolerated in this transformation, giving good yields and excellent enantioselectivities. $N$-heterocycles such as indoline (3f) and tetrahydroquinoline $(\mathbf{3 g})$, which are structural motifs commonly found in bioactive molecules, also served as competent substrates. Steric hinderance from nitrogen substituents did not significantly interfere with enzyme performance, giving $>70 \%$ yields and $98 \%$ e.e. (3b and 3c). L7_FL also 
displayed high activity toward primary anilines $(\mathbf{3 h}-\mathbf{m})$ bearing various substitution patterns on the aromatic ring, including a sterically hindered substrate with two ortho-substituents (3m). Arguably, aliphatic amines are significantly more challenging than anilines for asymmetric $\mathrm{N}-\mathrm{H}$ insertion reactions due to their increased Lewis basicity at the nitrogen atom ${ }^{17}$. To our delight, L7_FL was able to accept these amines, primary (3n-p) or secondary (3q), for the desired transformations, furnishing the corresponding $\alpha$-amino lactone products with good activities and enantioselectivities.
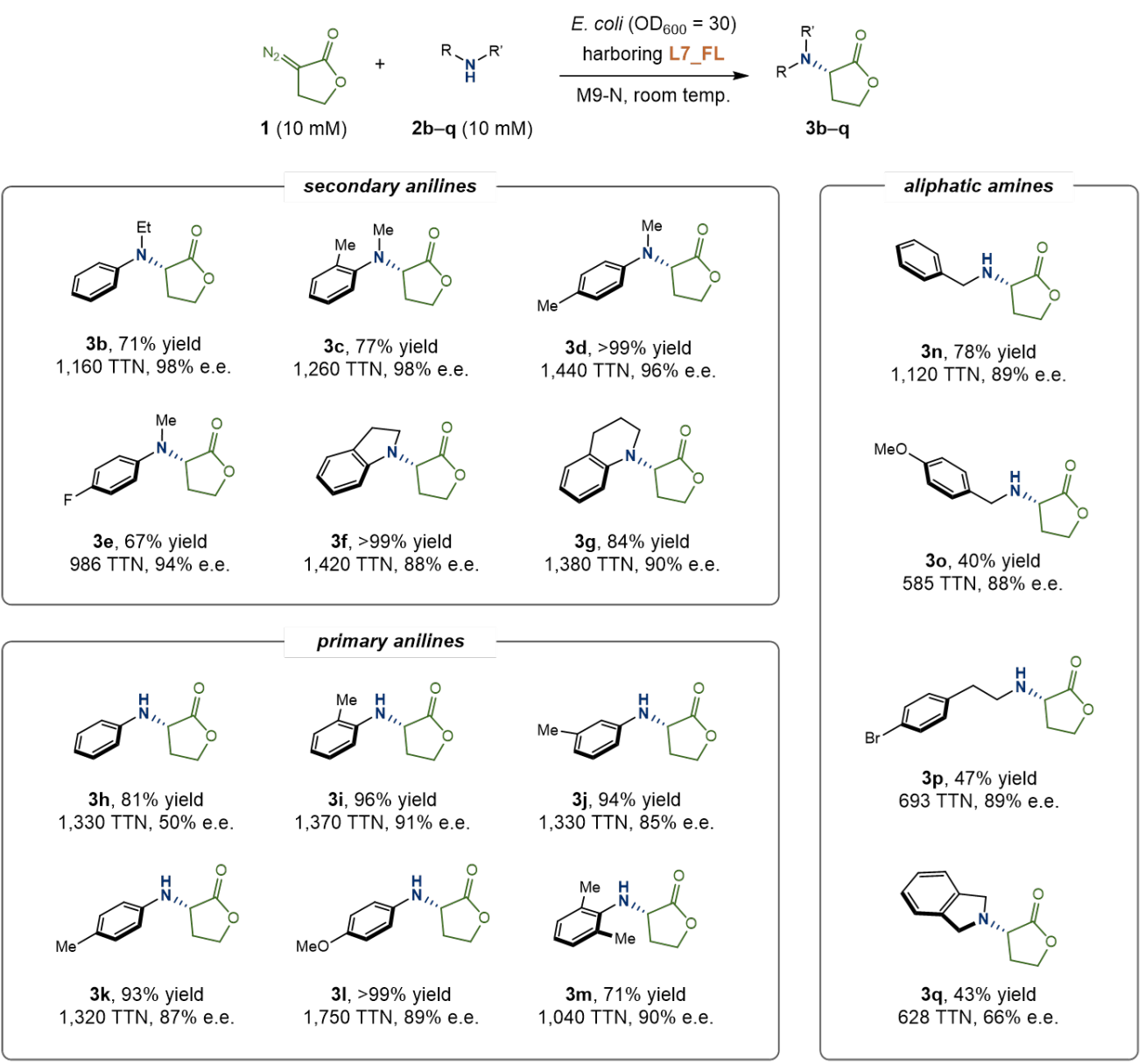

Fig. 4 | Enantioselective carbene $\mathrm{N}-\mathrm{H}$ insertion of secondary, primary anilines and aliphatic amines. The experiments were performed using E. coli $\left(\mathrm{OD}_{600}=30\right)$ that expressed the L7_FL enzyme with $10 \mathrm{mM}$ diazo 1 and $10 \mathrm{mM}$ amine (2b-q) at room temperature under anaerobic conditions. See SI for details.

To demonstrate the utility of this biocatalytic platform, we pushed the limit of the enzyme's catalytic capability by using much lower enzyme loadings. Under the standard conditions using whole-cell catalysts at $\mathrm{OD}_{600}=30$, the TTNs of the reactions are typically in the range of 1,000-2,000 (Fig. 4). Gratifyingly, lowering the amount of whole-cell catalyst did not result in a substantial drop in product formation, giving TTNs of 9,640 $\left(\mathrm{OD}_{600}=5\right)$ and 32,100 $\left(\mathrm{OD}_{600}=1\right)$ and showing that the enzymatic platform is particularly robust for this asymmetric amination chemistry (Fig. 5a). In addition, the enzymatic reactions are readily scalable (Fig. 5b). Using $N$-methyl-p-toluidine (2d) as the amine source, the $\mathrm{N}-\mathrm{H}$ insertion reaction was performed at gram scale, delivering product $\mathbf{3 d}$ in $97 \%$ isolated yield and $96 \%$ e.e. Products $3 \mathbf{e}$ and 31 were prepared at 1-mmol scale, with crystal structures determined by $\mathrm{X}$-ray crystallography. Finally, this enzymatic amination strategy was applied to the formal synthesis 
of the $(S)$-enantiomer of a fungicide, ofurace ${ }^{30,31}$. Key intermediate $\mathbf{3} \mathbf{m}$ was prepared via enzymatic $\mathrm{N}-$ $\mathrm{H}$ insertion with $72 \%$ isolated yield and $91 \%$ e.e.
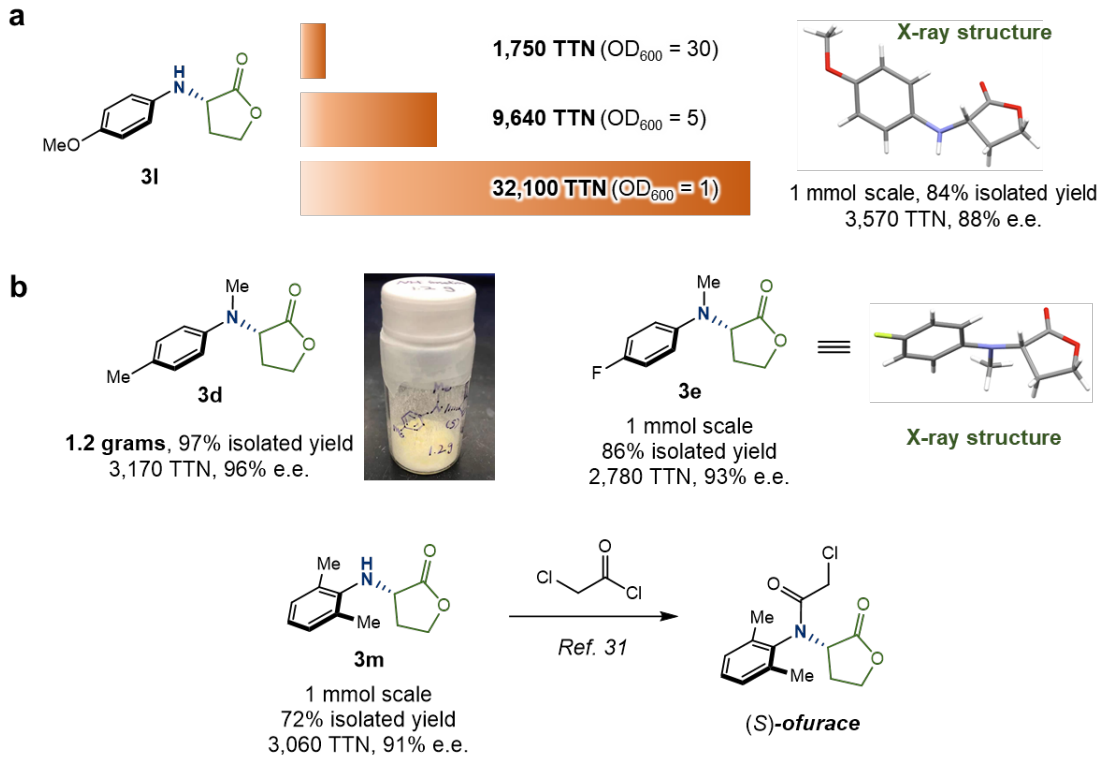

Fig. 5 | Investigation of the catalytic efficiency of L7_FL and scale-up of asymmetric N-H insertion reactions. a, Excellent TTNs (up to 32,100) were achieved with L7_FL when performing the enzymatic reaction with $\mathbf{2 l}$ at low $\mathrm{OD}_{600}$. $\mathbf{b}$, Preparative-scale reactions were carried out with $\mathbf{2 l}, \mathbf{2 d}$, $\mathbf{2 e}$ and $\mathbf{2 m}$. The X-ray crystal structures of $\mathbf{3 l}$ and $\mathbf{3 e}$ were obtained, and their absolute stereochemistry is consistent with the computational studies.

\section{Summary and Conclusion}

In summary, we developed an enzymatic platform for highly enantioselective carbene $\mathrm{N}-\mathrm{H}$ insertion reactions to furnish a set of biologically relevant $\alpha$-amino lactone products. The engineered P411 enzyme L7_FL acted as a dual-function biocatalyst that promoted the transfer of the lactone carbene to amines and exerted excellent stereocontrol in the subsequent protonation step. Computational studies elucidated the detailed mechanism of this fascinating process, explaining the critical role of the serine residue at position 264 for achieving high activity and selectivity. The engineered active site controls the conformation of the lactone carbene, yielding to an enantioselective $N$-nucleophilic attack for the ylide formation; it also precisely positions water molecules for rapid and stereoselective proton rearrangement before product release. Furthermore, we demonstrated that this enzymatic system can accept a broad range of amines for the desired amination reactions with high activity and enantioselectivity (up to $>99 \%$ yield and $98 \%$ e.e.). The enzyme was shown to be robust, achieving high turnover numbers (e.g., 32,100 TTN with 2l) and catalyzing these reactions in preparative scale, including preparation of a key intermediate for synthesis of $(S)$-ofurace. We envision that this highly efficient system can be applied to the preparation of bioactive chiral amines for synthetic chemistry and drug discovery.

\section{Data availability}

All data necessary to support the paper's conclusions are available in the main text and the Supporting Information. X-ray crystal structures of 3e (CCDC 2065484) and 31 (CCDC 2065489) are available free of charge from the Cambridge Crystallographic Data Centre via www.ccdc.cam.ac.uk/data_request/cif. 
Plasmids encoding the enzymes reported in this study are available for research purposes from F.H.A. under a material transfer agreement with the California Institute of Technology.

\section{References}

1. Hili, R. \& Yudin, A. K. Making carbon-nitrogen bonds in biological and chemical synthesis. Nat. Chem. Biol. 2, 284-287 (2006).

2. Froidevaux, V., Negrell, C., Caillol, S., Pascault, J.-P. \& Boutevin, B. Biobased amines: from synthesis to polymers; present and future. Chem. Rev. 116, 14181-14224 (2016).

3. Bariwal, J. \& Van der Eycken, E. C-N bond forming cross-coupling reactions: an overview. Chem. Soc. Rev. 42, 9283 (2013).

4. Kim, J. E., Choi, S., Balamurugan, M., Jang, J. H. \& Nam, K. T. Electrochemical C-N bond formation for sustainable amine synthesis. Trends Chem. 2, 1004-1019 (2020).

5. Kohls, H., Steffen-Munsberg, F. \& Höhne, M. Recent achievements in developing the biocatalytic toolbox for chiral amine synthesis. Curr. Opin. Chem. Biol. 19, 180-192 (2014).

6. Doyle, M. P. Catalytic methods for metal carbene transformations. Chem. Rev. 86, 919-939 (1986).

7. Liu, B., Zhu, S.-F., Zhang, W., Chen, C. \& Zhou, Q.-L. Highly enantioselective insertion of carbenoids into $\mathrm{N}-\mathrm{H}$ bonds catalyzed by copper complexes of chiral spiro bisoxazolines. J. Am. Chem. Soc. 129, 5834-5835 (2007).

8. Lee, E. C. \& Fu, G. C. Copper-catalyzed asymmetric N-H insertion reactions: couplings of diazo compounds with carbamates to generate $\alpha$-amino acids. J. Am. Chem. Soc. 129, 12066-12067 (2007).

9. Hou, Z. et al. Highly enantioselective insertion of carbenoids into $\mathrm{N}-\mathrm{H}$ bonds catalyzed by copper(I) complexes of binol derivatives. Angew. Chem. Int. Ed. 49, 4763-4766 (2010).

10. Arredondo, V., Hiew, S. C., Gutman, E. S., Premachandra, I. D. U. A. \& Van Vranken, D. L. Enantioselective palladium-catalyzed carbene insertion into the $\mathrm{N}-\mathrm{H}$ bonds of aromatic heterocycles. Angew. Chem. Int. Ed. 56, 4156-4159 (2017).

11. Wang, Z. J., Peck, N. E., Renata, H. \& Arnold, F. H. Cytochrome P450-catalyzed insertion of carbenoids into N-H bonds. Chem. Sci. 5, 598-601 (2014).

12. Sreenilayam, G. \& Fasan, R. Myoglobin-catalyzed intermolecular carbene N-H insertion with arylamine substrates. Chem. Commun. 51, 1532-1534 (2015).

13. Steck, V., Carminati, D. M., Johnson, N. R. \& Fasan, R. Enantioselective synthesis of chiral amines via biocatalytic carbene N-H insertion. ACS Catal. 10, 10967-10977 (2020).

14. Steck, V., Sreenilayam, G. \& Fasan, R. Selective functionalization of aliphatic amines via myoglobin-catalyzed carbene N-H insertion. Synlett 31, 224-229 (2020).

15. Coelho, P. S., Brustad, E. M., Kannan, A. \& Arnold, F. H. Olefin cyclopropanation via carbene transfer catalyzed by engineered cytochrome P450 enzymes. Science 339, 307-310 (2013).

16. Zhang, R. K. et al. Enzymatic assembly of carbon-carbon bonds via iron-catalysed $s p^{3} \mathrm{C}-\mathrm{H}$ functionalization. Nature 565, 67-72 (2019).

17. Liu, Z. \& Arnold, F. H. New-to-nature chemistry from old protein machinery: carbene and nitrene transferases. Curr. Opin. Biotechnol. 69, 43-51 (2021).

18. Chen, K. \& Arnold, F. H. Engineering new catalytic activities in enzymes. Nat. Catal. 3, 203$213(2020)$.

19. Ren, Y.-Y., Zhu, S.-F. \& Zhou, Q.-L. Chiral proton-transfer shuttle catalysts for carbene insertion reactions. Org. Biomol. Chem. 16, 3087-3094 (2018).

20. Li, M.-L., Yu, J.-H., Li, Y.-H., Zhu, S.-F. \& Zhou, Q.-L. Highly enantioselective carbene insertion into N-H bonds of aliphatic amines. Science 366, 990-994 (2019). 
21. Sharon, D. A., Mallick, D., Wang, B. \& Shaik, S. Computation sheds insight into iron porphyrin carbenes' electronic structure, formation, and $\mathrm{N}-\mathrm{H}$ insertion reactivity. J. Am. Chem. Soc. 138, 9597-9610 (2016).

22. Pavlović, D. et al. Synthesis and structure-activity relationships of $\alpha$-amino- $\gamma$-lactone ketolides: a novel class of macrolide antibiotics. ACS Med. Chem. Lett. 5, 1133-1137 (2014).

23. DeAngelis, A., Dmitrenko, O. \& Fox, J. M. Rh-catalyzed intermolecular reactions of cyclic $\alpha$ diazocarbonyl compounds with selectivity over tertiary C-H bond migration. J. Am. Chem. Soc. 134, 11035-11043 (2012).

24. Sattely, E. S., Meek, S. J., Malcolmson, S. J., Schrock, R. R. \& Hoveyda, A. H. Design and stereoselective preparation of a new class of chiral olefin metathesis catalysts and application to enantioselective synthesis of quebrachamine: catalyst development inspired by natural product synthesis. J. Am. Chem. Soc. 131, 943-953 (2009).

25. Chen, K., Zhang, S.-Q., Brandenberg, O. F., Hong, X. \& Arnold, F. H. Alternate heme ligation steers activity and selectivity in engineered cytochrome P450-catalyzed carbene-transfer reactions. J. Am. Chem. Soc. 140, 16402-16407 (2018).

26. Zhou, A. Z., Chen, K. \& Arnold, F. H. Enzymatic lactone-carbene C-H insertion to build contiguous chiral centers. ACS Catal. 10, 5393-5398 (2020).

27. Brandenberg, O. F., Chen, K. \& Arnold, F. H. Directed evolution of a cytochrome P450 carbene transferase for selective functionalization of cyclic compounds. J. Am. Chem. Soc. 141, 8989-8995 (2019).

28. Garcia-Borràs, M. et al. Origin and control of chemoselectivity in cytochrome $c$-catalyzed carbene transfer into Si-H and N-H bonds. ChemRxiv (2021) doi:10.26434/chemrxiv.14102363.v1.

29. Khade, R. L. \& Zhang, Y. Catalytic and biocatalytic iron porphyrin carbene formation: effects of binding mode, carbene substituent, porphyrin substituent, and protein axial ligand. J. Am. Chem. Soc. 137, 7560-7563 (2015).

30. Fisher, D. J. \& Hayes, A. L. Mode of action of the systemic fungicides furalaxyl, metalaxyl and ofurace. Pestic. Sci. 13, 330-339 (1982).

31. Kunz, W. \& Kristinsson, H. Bildung von 4-, 5- und 6gliedrigen Heterocyclen durch ambidoselektive Ringschlüsse von Enolat-Ionen. Helv. Chim. Acta 62, 872-881 (1979).

\section{Acknowledgements}

This work was supported by the NSF Division of Molecular and Cellular Biosciences (grant 2016137 to F.H.A.), the US Army Research Office Institute for Collaborative Biotechnologies (cooperative agreement W911NF-19-2-0026 to F.H.A.), the Spanish Ministry of Science and Innovation MICINN (grant PID2019-111300GA-I00 to M.G.B), and the Generalitat de Catalunya AGAUR Beatriu de Pinós H2020 MSCA-Cofund (2018-BP-00204 project to M.G.B.). K.C. thanks the Resnick Sustainability Institute at Caltech for fellowship support. The computer resources at MinoTauro and the Barcelona Supercomputing Center BSC-RES are acknowledged (RES-QSB-2020-2-0016). We thank David C. Miller, Sabine Brinkmann-Chen, Ravi Lal, and Tian Zeng (May) for helpful discussions and comments on the manuscript. We further thank Mona Shahgholi for HRMS analysis and Michael K. Takase for $\mathrm{X}$-ray crystallographic analysis.

\section{Author contributions}

Z.L. and K.C. conceived and designed the overall project with F.H.A. providing guidance. Z.L. and A.Z.Z. designed and performed the initial screening of haem proteins and the substrate scope study. 
C.C.T. and M.G.B. carried out the computational studies. Z.L., K.C., M.G.B. and F.H.A. wrote the manuscript with the input of all authors.

\section{Competing interests}

A provisional patent application based on this manuscript has been filed through the California Institute of Technology. 